\begin{tabular}{|c|c|c|}
\hline $\begin{array}{l}\text { EXCELLENT } \\
\text { PUBLISHERS }\end{array}$ & 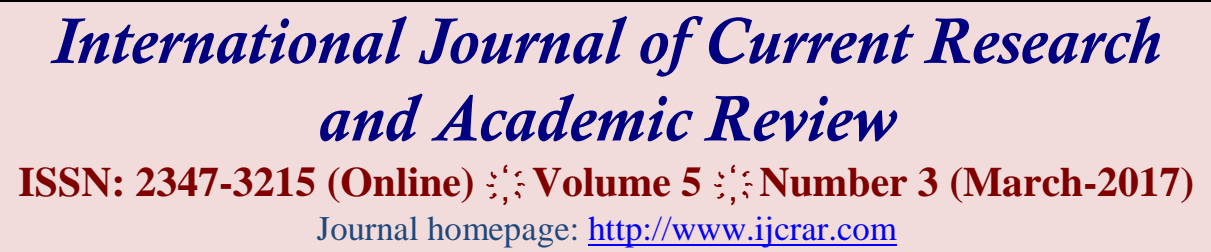 & Istist \\
\hline
\end{tabular}

doi: https://doi.org/10.20546/ijcrar.2017.503.008

\title{
Ovarian Cyst in Pediatric Age Group
}

\author{
Asseel Jaleel Ibraheem Harba ${ }^{1}$ and Kawthar Fakhri ${ }^{2}$
}

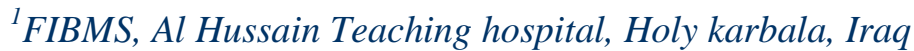

${ }^{2}$ FIBMS, Baghdad Medical city, Baghdad-Iraq

*Corresponding author

\begin{abstract}
Ovarian cyst in pediatric age group is unusual condition that can be found incidentally or can be present as a condition with signs and symptoms, it can be discovered antenatal with routine maternal US or can show itself by its own effect or its effect on the surrounding structures. Mode of management range from simple observation, simple surgical interference, elective operation or as emergency condition. Objective to study the clinical and histopathological characteristics of ovarian cysts among group of Iraqi pediatric patients.
\end{abstract}

\section{Article Info}

Accepted: 28 February 2017

Available Online: 20 March 2017

\section{Keywords}

Ovarian cyst, clinical and histopathological characteristics Pediatric age

\section{Introduction}

Despite ovarian cysts are rare condition in pediatric age group they are still significant health problem faced by pediatric surgeon during their surgical practice worldwide, from other point of view during the last years with advancing in the diagnostic techniques and widespread availability and use of pelvic sonography as a non-invasive method, the detection of ovarian cysts in pediatric population became more frequent and the rate of detection much increased. Different factors might interfere with the proper management of ovarian cysts; patient's age, symptoms, menarchal status, size of the cysts and their properties in addition to the associated medical conditions all should be taken into account when managed a case with ovarian cyst, based on the aforementioned factors the management strategies are determined.

Ovarian cysts characterized by different clinical presentations, hence different types and timing of treatment are needed to prevent the developing of complications such as ovarian necrosis after torsion which represent a surgical emergency (Ryan et al., 2012). The etiology of ovarian cysts varies with the developmental stage and hormonal milieu of the patient. In general, most ovarian cysts are functional in nature and usually resolve without treatment. All surgical procedures for ovarian cysts should spare functional ovary as much as is technically possible. Simple cysts should be fenestrated. Complex or functional cysts should be excised, with preservation of the remaining ovary (Tessiatore et al., 2012; Brandt et al., 2005). Ovarian tissue arises from three separate areas of the embryo; the mesenchyme of the urogenital ridge, the germinal epithelium that covers the urogenital ridge and the germ cells which arise in the yolk sac.

Follicles in the ovary develop from all this layers. Ovary lays under the influence of hormonal effect at all time, first under the hormonal effect of the mother estrogen, placenta gonadotropin and fetal gonadotropin which is full down till the age of 6-8 month post term then the FSH and LH of the neonate which decrease later on. So the ovarian cyst can be present antenatal and discovered by routine maternal US or can be present later on, pre- 
pubertal age group has the high percentage because of the hormonal effect FSH and LH (Brandt et al., 2005; Papic et al., 2014).

Most of the cysts are functional and can be manage conservatively. The effect of the cyst may be because of its hormonal effect leading to precocious puberty or it may cause pressure effect on its surrounding structures leading to chronic abdominal pain, dysuria, hydronephrosis and even obstruction to the large bowel, the malignant mass is rare.

\section{Materials and Methods}

A total of 31 pediatric female cases aged few days to 12 years were enrolled in this prospective study which was conducted at Al-Hussain teaching hospital in Holey Karbala province (middle of Iraq) and Baghdad Medical City in Baghdad (Capital of Iraq) during the period 2013 to the the mid of 2016.

After ethical issues confirmation from the parents or care givers of the patients and official authorities, demographic and clinical data of the patients were obtained and reported. The cases selected from those who attended the pediatric surgery department and outpatient clinic with different presentations such as Abdominal mass with distended abdomen, Obstructed an inguinal hernia and abscess formation, Chronic abdominal pain and acute abdomen suspected as appendicitis. Abdominal sonography was performed for all patients pre-operatively and the findings were reported then the management was decided according to the clinical findings and final diagnosis of the patients. However most of the patients presented as acute abdomen and managed as an emergency case.

Different surgical approaches and incisions were used in the management of the patients including according to the suspected underlying pathology so transverse or pfannenstiel, midline incisions and lymph node biopsy was taken in some cases, gridiron incision and paramedian incision accordingly.

\section{Results and Discussion}

The age distribution (few days to 12 years) and majority of the cases aged 6-12 years which is similar to most of other researches, who reported ovarian cysts in such age group (Jennifer, 2017) (Table 1). Most of the patients had history of chronic abdominal pain and frequent attacks of nausea and vomiting, none of the cases have menstrual history, only three patient were obese, 7 patients have UTI and one with lymphoma.

Out of the 31 cases, 13 (41.9\%) presented as acute abdomen with twisted ovarian cysts this results draw attention to the role of ultrasonography (US) in early diagnoses of the cyst and close observation to its size and consistency and timing of operation so that decrease the chance of complication and increase the possibility of ovarian salvage and to differentiate between acute appendicitis and ovarian cyst and managed accordingly (Eleftheriade et al., 2004). Twisted ovarian cyst is one of the complication that lead to loss of the ovary in most cases. Other factors could also contribute as missed diagnosis of abdominal pain, loss of close observation of a diagnosed cyst and late surgical interference all this can lead to loss of the ovary which can be salvage by proper early intervention even in twisted cyst that could be retwisted and preserve the ovary if it is not gangrenous (Carol et al., 2011; HongqianLiu et al., 2013). Most of the patients with RT side cysts, previous studies also reported higher rate of the right sided cysts (Pienkowski et al., 2012).

One of our patients has right inguinal hernia and ovarian cyst proved by ultrasonography (US). Unfortunately, the parents of that patient refuse surgery and then end as obstructed and managed as emergency case, 5 of the 31 cases have no abdominal US pre-op and presented with features like acute appendicitis and history of recurrent attack of abdominal colicky pain with neonatal abdominal mass, US proved the presence of cystic mass, Two patients with chocolate masses not resolved by conservative measure for 2 months, in 5 cases US showed complex masses and proved twisted ovarian cyst. Most of the cases managed as an emergency case because of presentation as acute abdomen as twisted ovarian cyst 5 cases, 7 cases as semi-emergency case (neonatal abdominal mass), 2 cases as acute appendicitis, 4 cases as elective operation for adenexal mass and 1 case as obstructed inguinal hernia. Inguinal incision (in case with obstructed hernia) was performed in one case, grid iron incision in 5 cases, transverse lower abdominal incision either RT or LT side in 19 cases, pfannenstiel incision in 4 cases, and longitudinal incision in two cases (Table 2). The etiology of ovarian cysts varies with the developmental stage and hormonal milieu of the patient, generally most of the ovarian cysts are functional in nature and can be managed conservatively, complex masses should be managed surgically to prevent its complications as twisted ovary and to detect abnormal pathology that can converted to malignancy the role of 
abdominal and pelvic US is very important to decide the time of the operation and type of incision (Table 3). In the current study most of our cohort has pre-operative US so that some of them managed as emergency case while others as elective case. Hence the time of operation is very important where the more the early detecting ovarian cyst the more chance to preserve the ovary even twisted ovary can be preserved if detected early and managed properly. In the present study, ovary was preserved in 9 cases by doing cystectomy only.

The surgical incision in these cases varies according to the suspicion pathology, in cases with simple cysts transverse or pfannenstiel incisions were performed while in a case with suspected malignant lesion midline incision was used for proper exposure and lymph node biopsy (Table 4).

Table.1 Age distribution of the studied group $(\mathrm{N}=31)$

\begin{tabular}{|l|c|c|}
\hline Age & Number of patients & $\%$ \\
\hline Neonate and infancy & 7 & 22.6 \\
\hline 2-5 years & 1 & 3.2 \\
\hline 6-12 year & 23 & 74.2 \\
\hline Total & 31 & 100.0 \\
\hline
\end{tabular}

Table.2 Main presentations of the studied group $(\mathrm{N}=31)$

\begin{tabular}{|l|c|c|}
\hline \multirow{2}{*}{ Presentation } & \multicolumn{2}{|c|}{ Neonate and infancy } \\
\cline { 2 - 3 } & No. & $\%$ \\
\hline Abdominal mass with distended abdomen & 7 & 22.6 \\
\hline Obstructed an ingunal hernia and abscess formation & 1 & 3.2 \\
\hline Chronic abdominal pain and acute abdomen & 23 & 74.2 \\
\hline Total & 31 & 100.0 \\
\hline
\end{tabular}

Table.3 Types of incisions ( $\mathrm{N}=31)$

\begin{tabular}{|l|c|c|}
\hline Incisions & No. & $\%$ \\
\hline Transverse abdominal & 19 & 61.3 \\
\hline Gridiron incision & 5 & 16.1 \\
\hline Pfannenstiel incision & 4 & 12.9 \\
\hline Paramedian incision & 2 & 6.5 \\
\hline Inguinal incision & 1 & 3.2 \\
\hline
\end{tabular}

Table.4 Types of pathologies detected among the studied group $(\mathrm{N}=31)$

\begin{tabular}{|l|c|c|}
\hline Pathology & No. & $\%$ \\
\hline Simple cyst & 4 & 12.9 \\
\hline Gangrenous cyst & 10 & 32.3 \\
\hline Chocolate cyst & 2 & 6.5 \\
\hline Mature teratoma & 8 & 25.8 \\
\hline Immature teratoma & 3 & 9.7 \\
\hline Tumor & 1 & 3.2 \\
\hline Dermoid cyst & 3 & 9.7 \\
\hline
\end{tabular}


Fig.1 Side of ovarian cyst among the studied group

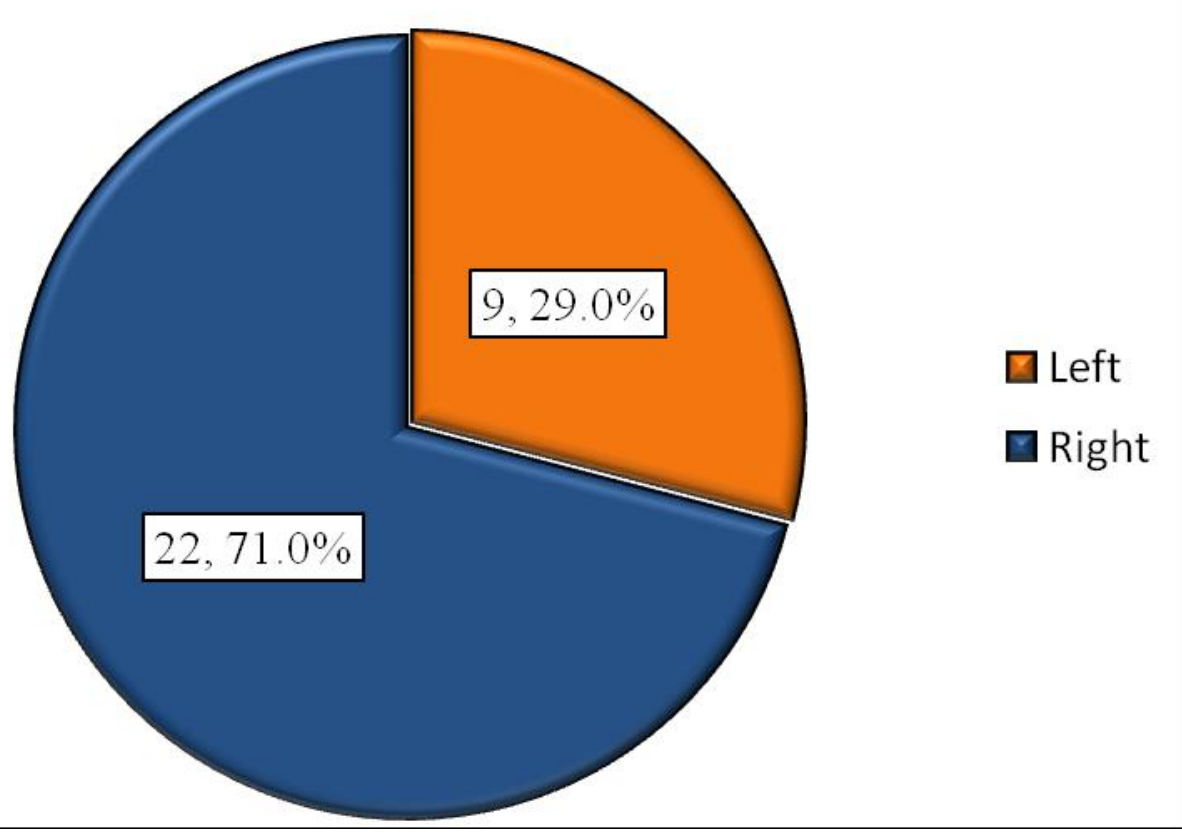

One case with malignancy found in our research the complex masses were mature teratoma proved by histopathological exam post op and tow with chocolate cyst and one with immature teratoma (Pienkowski et al., 2012; Croitoru et al., 1991) so no follow up with the patient and just 2 cases send for b-HCG and AFP and both were within normal range. No complication recorded after operation with all types of surgical incisions and all presentation even with gangrenous ovaries,

No drain put apart from the abscess drainage and only three patients had appendectomy. In the neonatal age group most of the cysts were functional simple cyst and managed conservatively and all attempt should be made to preserve the ovary with minimal surgical interference by using transcutaneous drainage under US guide or by using laparoscopic technique which we have only one experience with it till now (Helmrath et al., 1998). However, Ovarian pathology although it is a rare in children it must be included in the differential diagnosis of all girls who present with abdominal pain, an abdominal mass or precocious puberty (Jennifer, 2017; Kuroiwa et al., 2004).

\section{Conclusions and Recommendations}

1. Most cases presented and managed as emergency cases.
2. Patients with complex masses were surgically managed and simple cysts were conservatively closely observed.

3. None of the cases developed complications.

4. Ultrasonography, is a non-invasive, safe, available and good informative test with significant role in early diagnoses and proper management.

5. Tumor markers should be assessed in suspected malignancy cases

6. Ovarian tissue should be preserved when possible by using minimally invasive technique and cystectomy only when it is possible.

\section{Acknowledgment}

Authors would like to express their great thanks and gratitude to the families of the patients for their participation in this study, and hope to have good health and life. Great thanks to everyone who support this work particularly the surgical teams and theater staff.

\section{References}

Bluth, E.I. 2000. Ultrasound: a practical approach to clinical problems. George Thieme Verlag, ISBN 978-0-86577-861-0. P 190 
Brandt, M.L.H.M. 2005. Ovarian cysts in infants and children. Semin. Pediatr. Surg., 14(2): 78-85.

Carol, T., Marcia, L. 2011. Diseases of human body. Philadelphia, PA: library of congress, 978-0-80362505-1.

Croitoru, D.P., Aaron, L.E., Laberge, J.M., Neilson, I.R., Guttman, F.M. 1991. Management of complex ovarian cysts presenting in the first year of life. $J$. Pediatric Surgery, 26(12): 1366-8.

Cronen, P.W., Nagaraj, H.S. 1988. Ovarian tumors in Children, South Med. J., 81: 464-8.

Darrell, L., Cass, Edith Hawkins, Mary, L., Brandt, M.C. 2001. Surgery for Ovarian Masses in Infants, Children, and Adolescents: 102 Consecutive Patients Treated in a 15-Year Period. J. Pediatr., 36(5): 693-9.

Eleftheriade, M., Shiadoes, V. 2004. The gold standard for diagnosing ovarian masses is US. (Ovarian mass during adolescence: clinical, ultrasonographic and pathological findings, serum tumor markers and endocrinological profile. Gynaecol. Endocrinol., 19: 1-8.

Helmrath, M.A., Shin, C.E., Warner, B.W. 1998. Ovarian cysts in the pediatric population. In Seminars in pediatric surgery, (Vol. 7, No. 1, pp. 19-28). WB Saunders.
Hongqian Liu, Xiangao Wang, Donghao Lu, Zhihong Liu and Gang Shi. 2013. ovarian masses in children and adolescents in china. J. Ovarian Res., 6: 47-52.

Jennifer eng-lunt, J.A. 2017. Pediatric and Adolescent Ovarian Torsion. ACEP, 3(13): 1-5.

Kuroiwa, M., Suzuki, N., Murai, H., Toki, F., Tsuchida, Y., Hatakeyama, S.I. 2004. Neonatal ovarian cysts: management with reference to magnetic resonance imaging. Asian J. Surgery, 27(1): 43-8.

Papic, J.C., Billmire, D.F., Rescorla, F.J., Finnell, S.M.E., Leys, C.M. 2014. Management of Neonatal Ovarian Cysts and its Effect on Ovarian Preservation. J. Pediatr. Surg., [Internet]. 49(6): 990-4. Available from: http://dx.doi.org/10.1016/j.jpedsurg.2014.01.040

Pienkowski, C., Cartault, A., Carfagna, L., Ernoult, P., Vial, J., Lemasson, F., et al. 2012. Ovarian cyst in pre-pubertal girls. Endocr. Dev., 22: 101-11.

Ryan, M.F., Desai, B.K. 2012. Case Report Ovarian Torsion in a 5-Year Old: A Case Report and Review. Hindawi Publ. Corp., 679121-3.

Tessiatore, P., Guanà, R., Mussa, A., Lonati, L., Sberveglieri, M., Ferrero, L.C.F. 2012. When to operate on ovarian cysts in children? J. Pediatr. Endocrinol. Metab., 25(5-6): 427-33.

Thind, C.R., Carty, H.M., Pilling, D.W. 1989. The role of ultrasound in the management of ovarian masses in children. Clin. Radiol., 40: 180-2.

\section{How to cite this article:}

Asseel Jaleel Ibraheem Harba, Kawthar Fakhri. 2017. Ovarian Cyst in Pediatric Age Group. Int.J.Curr.Res.Aca.Rev. 5(3), 48-52. doi: https://doi.org/10.20546/ijcrar.2017.503.008 